\title{
Soil freezing and the depth of spread foundations
}

\author{
Irena Ickiewicz ${ }^{1, *}$ \\ ${ }^{1}$ Bialystok University of Technology, Faculty of Civil Engineering and Environmental Engineering, \\ Poland
}

\begin{abstract}
This paper presents the possibility for setting heated building foundations at a depth lower than the level of „zero" isothermal line. In order for the foundation not to be susceptible to damage due to its exposure to negative temperatures, an appropriate thermal insulation was proposed. For the suggested thermal insulation - by means of numerical methods - a calculation of temperature distribution in the vicinity of the foundations was carried out. Based on the analysis of the obtained results, an optimal setting depth for insulated foundations was proposed.
\end{abstract}

\section{Introduction}

A natural ground temperature field exists far away from various heat sources and is a function of time and depth. A natural temperature field is influenced mainly by the fluctuations of exterior air and average annual temperatures. Apart from air temperature fluctuations, a natural temperature field can be also influenced by various heat sources such as: buildings (especially heated ones), high-voltage transmission lines, sewage, piping, heat supply mains etc. The influence of such heat sources is extremely complex and, as such, difficult to determine.

The knowledge of ground temperature field and especially the location of the "zero" isothermal line (identified with the depth of freezing) is especially important for practical engineering. The depth of soil freezing (mostly for swelling soils) has significant impact on the depth of buildings' spread foundations and on designing thermal insulation that protects the foundation against frost.

Currently in Poland, the depth of spread foundations (determined solely by the depth of soil freezing) vary, depending on the climate zone and is respectively: I zone $-0.8 \mathrm{~m}$, II - $1.0 \mathrm{~m}$, III - $1.2 \mathrm{~m}$ i IV $-1.4 \mathrm{~m}$.

\section{Determining a safe freezing depth of building foundation settings}

In Poland, the depth of spread foundations $h_{z}$ is determined by the PN-03020 norm: Designing Spread Foundations. The condition for a foundation setting that is shallower than recommended is its proper protection against frost heaving by using appropriate thermal

*Corresponding author: i.ickiewicz@pb.edu.p1 
insulation or foundation heating. The continuous lack of guidelines for protecting foundations against freezing causes the norm entry to be a dead letter.

\subsection{The maximum location values of zero isothermal line in soils without a building interference}

Among the methods for determining soil freezing applied in Poland, the number of degreedays for negative temperatures, factors dependent on soil type, and snow cover thickness are primarily utilized. That is why, the distribution of soil temperature (in open space) is impacted by variable exterior conditions such as air temperature (also before the period of negative temperatures), the type of soil and soil moisture content, as well as snow covering (its thermal conductivity or time-variable density). Table 1 displays the selected maximum annual depth of the zero isothermal line recorded in Poland between 1980/81 and 2011/2012 (for 30 winters) and 12 Polish cities. The data has been sourced from the appendix 2 to the "On Soil Freezing in Poland" [5] monograph.

Table 1. Maximum values of ,zero" isothermal line location.

\begin{tabular}{|c|c|c|}
\hline Year & H $^{*}$ Value & City \\
\hline $1995 / 96$ & 1.18 & Bialystok \\
\hline $1995 / 96$ & 1.10 & Chojnice \\
\hline $1995 / 96$ & 1.20 & Kielce \\
\hline $1995 / 96$ & 1.08 & Poznań \\
\hline $1995 / 96$ & 1.48 & Włodawa \\
\hline $2005 / 2006$ & 1.10 & Poznań \\
\hline
\end{tabular}

The conclusion drawn from the values compiled in the above table is that, across 30 years, it was only during two winters that the location of zero isothermal line took place at the depth of $>1 \mathrm{~m},{ }^{*} \mathrm{~h}-$ depth in $[\mathrm{m}]$.

\subsection{Maximum location values of zero isothermal line in soils with a building interference}

When it comes to the temperature distribution in the vicinity of building foundations, the natural temperature field is interrupted by the building itself (even when it is not heated). For that reason, the values of isothermal line location are more favorable to the construction of foundations. A big role in protecting the foundation against freezing is attributed also to the insulation of foundations. It is important to keep in mind, however, that the thickness of snow covering (protecting the soil against freezing) should not be taken into consideration, due to the fact that - in most cases - the snow deposited in the vicinity of buildings is being regularly removed. Determining the setting depth for foundations should pertain to extreme conditions.

\subsubsection{Calculation model}

Apart from air temperature, partitions adjacent to the soil such as the floor and the walls of surfaces terminated below the ground level, have an influence on the temperature changes in soils located under the building. Heat losses of these partitions are to be considered as a model consisting of building ground. Among multiple calculation models, the best result 
congruence is displayed by the Henrikson model [4]. This model assumes that - within the building's floor area -2 zones can be identified and that the entire heat stream can be divided into 2 components:

$$
Q_{\mathrm{o}}=Q_{1}+Q_{2}
$$

where:

$Q_{1}$ - determines the heat flow through parts of the floor around external walls, the heat loss of which is subject to fluctuations depending on the changes in the temperature of exterior air.

$Q_{2}$ - pertains to the middle part of the building's floor, on which air changes have no influence.

Within the area removed by less than $\boldsymbol{r}$ from the axis of the exterior wall, the permeation of heat occurs in circles of radius of $\rho<\mathrm{r}$. For a surface area removed by more than ,r” from the axis of the exterior wall, it is assumed that the isothermal line of multi-year average is placed within the plane of the exterior wall's axis and in circles with a radius of $\mathrm{r}<\rho<B / 2$ ( $B-$ building's width).

In such a situation, the heat flux is expressed as:

$$
Q=U_{1}\left(t_{1}-t_{\mathrm{e}}\right) r++U_{2}\left(t_{1}-t_{s}\right)(B / 2-r)
$$

where:

$U_{1}, U_{2}$ - heat penetration rate for zones 1 and 2 respectively,

$t_{1}$ - air temperature inside the building,

$t_{\mathrm{e}}$ - ground surface temperature at a high depth under the building, subject to calculations,

$t_{\text {sr }}-$ soil temperature at a high depth under the building,

$B$ - building's width.

Analyses carried out by Henrikson [5] concluded that the boundary zone's width, where a noticeable exterior temperature influence on the building-soil system is observed equals $0,75 \mathrm{~m}$.

\subsubsection{Calculations}

A calculation model was developed in order to determine the influence of buildings on the distribution of temperatures in soils around foundations. The model depicts a building without a basement, on strip foundations with dimensions of $40 \times 70 \mathrm{~cm}$, made out of ordinary concrete from stone aggregate, with the heat penetration rate $\lambda=1.8[\mathrm{~W} / \mathrm{m} \cdot \mathrm{K}]$. It was assumed that the building is set on soils with heat penetration rate of $\lambda=0.85[\mathrm{~W} / \mathrm{m} \cdot \mathrm{K}]$.

Both a heated building without a basement and the same building, but as an unheated object, were subject to analysis.

The following interior temperatures were assumed:

- in a heated building $\mathrm{T}_{\mathrm{i}}=+20^{\circ} \mathrm{C}$,

- in an unheated building $\mathrm{T}_{\mathrm{i}}=+5^{\circ} \mathrm{C}$.

Boundary conditions:

- heated building.

Surface $1-\mathrm{T}=$ const $=9.5^{\circ} \mathrm{C}$,

Surface $3-\mathrm{T}=$ const $=20^{\circ} \mathrm{C} ; \mathrm{R}_{\mathrm{si}}=0.17\left[\mathrm{~m}^{2} \cdot \mathrm{K} / \mathrm{W}\right]$,

Surface $4-\mathrm{T}=$ const $=20^{\circ} \mathrm{C} ; \mathrm{R}_{\mathrm{si}}=0.13\left[\mathrm{~m}^{2} \cdot \mathrm{K} / \mathrm{W}\right]$,

Surface 6-9 $-\mathrm{T}(\mathrm{t})=$ funct (linear function based on climate data (winter $86 / 87$ ),

$$
\mathrm{R}_{\mathrm{si}}=0.04\left[\mathrm{~m}^{2} \cdot \mathrm{K} / \mathrm{W}\right] \text {, }
$$

Surface 2, 5, 10 - adiabatic, $\mathrm{q}=0$. 


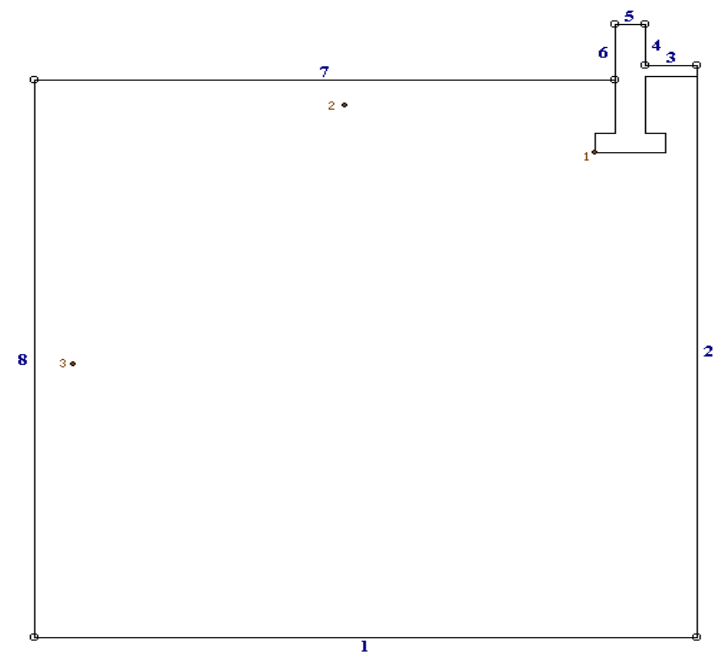

Fig. 1. Boundary conditions, the numbering of boundary surfaces and measurement points $(1,2,3)$.

Elevations of measurement points:

- Pt $1(8.7 ; 8.8)$ on the border of the foundation,

- Pt $2(4.8 ; 9.7)$ removed by $4.8 \mathrm{~m}$ from the building and $0.3 \mathrm{~m}$ below the ground level,

- Pt $3(7.0 ; 5.0)$ removed by $7 \mathrm{~m}$ from the building and depth of $5 \mathrm{~m}$.

Results from calculations for Bialystok from the coldest day (January 1987) depicted in Fig. 2.

a)

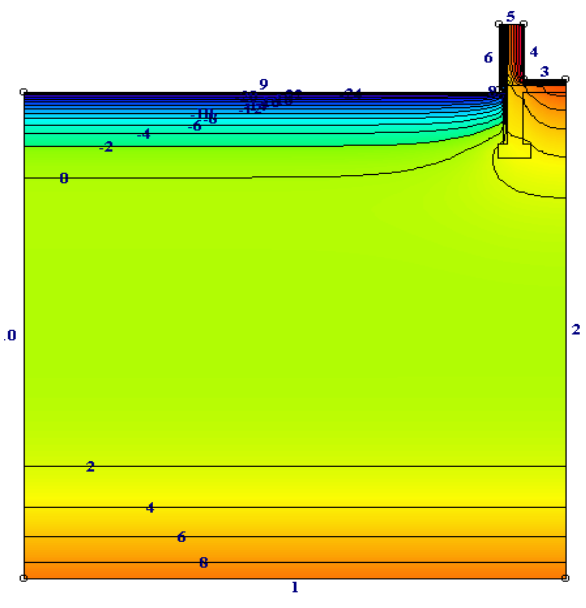

b)

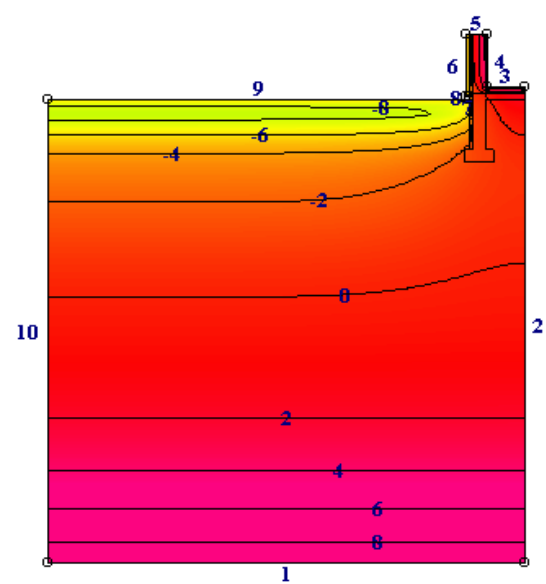

Fig. 2. An example of temperature distribution around the foundation of a heated building (a) and an unheated building (b), for the coldest day of winter in $86 / 87$, the foundation terminated below the ground level by $1.20[\mathrm{~m}]$, sand with coefficient $\lambda=0.85[\mathrm{~W} / \mathrm{m} \cdot \mathrm{K}]$.

Based on the analysis of source material [1, 2, 3] and the received results (Fig. 2), it can be concluded that the influence of a building on the distribution of temperature in the soil (during winter season) is significant only in close vicinity to the building which is equal to $0.60-0.70 \mathrm{~m}$.

The biggest influence of the heated building was observed on the depth of $0.50 \mathrm{~m}$. The differences are still visible at $2 \mathrm{~m}$ while at $4 \mathrm{~m}$ they are significantly diminished. 


\section{Thermal protection of foundations}

A number of numerically-assisted calculations were carried out in order to investigate whether - in Polish climate conditions (for winters with a 50-year return period) - buildings can be set at a depth lower than the one specified by the norm. The necessity to utilize numerical programs was brought about by the complex mathematical description of tasks associated with the analysis of temperature fields in soils with a building ,interference". The calculations were carried out for foundations set at the depth of $0.5 \mathrm{~m}$ and for various isolation thickness $(8-10 \mathrm{~cm}$ ). various types of soil (the value of heat penetration rate $\lambda$ from 0.85 to $1.9[\mathrm{~W} / \mathrm{m} \cdot \mathrm{K}])$.

The analysis of the influence of foundation heating on the temperature distribution in soil around a building was carried out based on the results of numerical calculations which were in part experimentally verified (direct IMiGW measurement and own measurements which were necessary for the verification of calculations).

The calculations of temperature values in selected points of the foundation were carried out using the HEAT 2 software (two-dimensional heat conductivity).

The following input data for calculations were defined:

- boundary conditions (air temperature for the selected winter of 2005/2006),

- the calculation model (adiabatic surfaces were set),

- thermo-physical properties of the analyzed soils.

The calculations were carried out for extreme weather conditions, that is for a winter with a 50-year return period. For that reason, the obtained results can be used to develop guidelines pertaining to the optimal heat insulation of foundation and ground soil against freezing.

The model took advantage of the Fourier heat conductivity equation for frozen and unfrozen soil (damp, below freezing front).

The solution to the heat conductivity equation was based on solving the relevant boundary value problem, that is a differential equation together with its accompanying boundary conditions and initial conditions. The result of this solution is a functional dependence of temperature on both the geometric coordinates and time.

The selected example results are shown in figures $4 a, 4 b$.

Presented in fig. 3 a,b, is a distribution of points where the calculations of temperature values were carried out, depending on the insulation variant, setting depth, type of soil, and the thickness of the thermal insulation layers. The foundations have been terminated below the ground level by $0.5 \mathrm{~m}$.

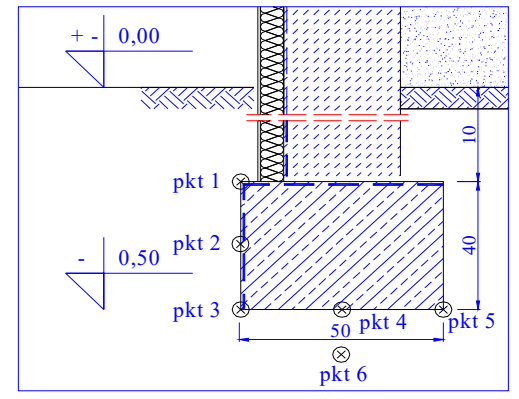

a)

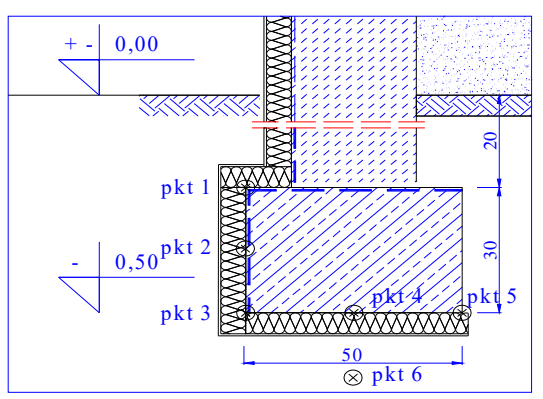

b)

Fig. 3. The analyzed construction-material solutions for foundations, the distribution of measurement points. a) variant with insulation only on the foundation wall b) variant with insulation on the foundation wall and the foundation strip (spread footing). 


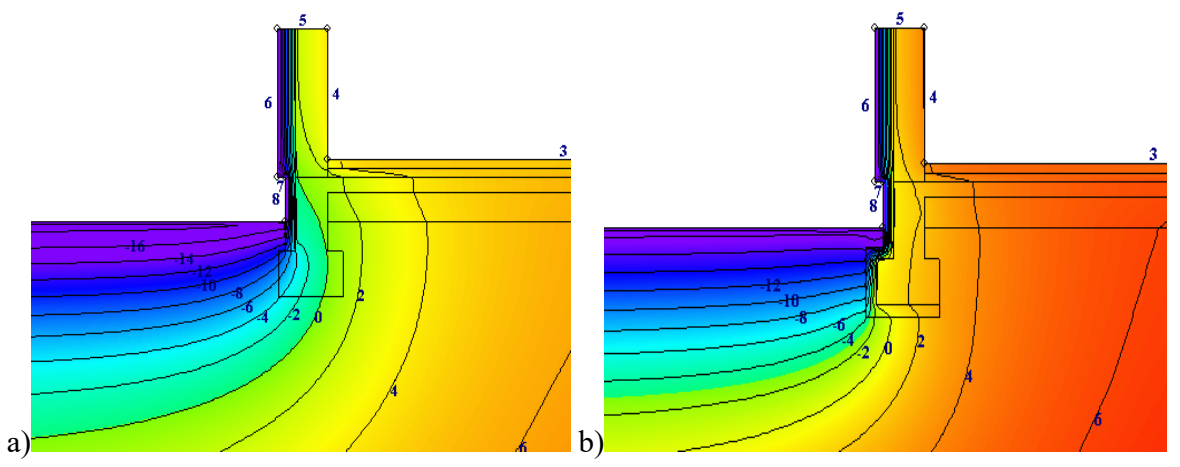

Fig. 4. The results of temperature distribution in ground in the vicinity of foundations. a) variant with insulation only on the foundation wall, styrofoam $8-\mathrm{cm}$ thick, b) variant with insulation on the foundation wall and the foundation strip (spread footing), styrofoam 8-cm thick.

Based on the analysis of obtained results (Fig. 4), the temperature values in selected points (Fig. 3) are being compiled in table 2. The lowest soil temperatures in the vicinity of foundations set at the depth of $50 \mathrm{~cm}$ occur in point no. 3 (the corner of the foundation strip of the spread footing viewed from the inside), and at the foundation junction under the foundation strip (spread footing) (p. no. 4.5) the temperatures are significantly higher and when the foundation strip is also insulated - are positive (p.4, from +0.5 to $+3.5^{\circ} \mathrm{C}$ ).

Table 2. Temperature values in points.

\begin{tabular}{|c|c|c|}
\hline point & $\begin{array}{c}\text { Variant a } \\
{\left[\mathbf{C}^{\mathbf{0}}\right]}\end{array}$ & $\begin{array}{c}\text { Variant b } \\
{\left[\mathbf{C}^{\mathbf{o}}\right]}\end{array}$ \\
\hline 1 & $-1,5$ & 0 \\
\hline 2 & $-1,0$ & 0 \\
\hline 3 & $-0,5$ & $+0,5$ \\
\hline 4 & $+1,0$ & +2 \\
\hline 5 & $+2,5$ & $+4,0$ \\
\hline
\end{tabular}

For the analyzed winter $(2005 / 2006)$ and soil $(\lambda=0.85[\mathrm{~W} / \mathrm{m} \cdot \mathrm{K}])$, negative temperatures at the junction of foundation strip with the soil (p. 3, 4, 5) can occur only in the case of an unheated building or a lack of thermal insulation of the wall and foundation strip.

\section{Summary and conclusions}

Based on the analysis of simulated calculation values, it can be concluded that the risk of negative temperatures (soil freezing) occurring in the vicinity of building foundations depends on:

- the factor of degree-days of negative temperatures $\mathrm{Fd}$,

- thermal-physical properties of the soils surrounding the foundation, mostly heat conductivity rate $\lambda$,

- the depth of foundation setting,

- the manner of building usage (exploitation); (heated and unheated building),

- the manner of thermal insulation of the foundation wall and the foundation itself. 
The condition for setting heated building foundations at the depth of $0.5 \mathrm{~m}$ (if there are no other reasons against it) is the insulation of both the foundation wall and the foundation strip with extruded styrofoam, at least $8 \mathrm{~cm}$ in thickness.

When it comes to buildings with prolonged pauses in heating, it is safer to set the foundation at the depth of at least $0.70 \mathrm{~cm}$ and insulate the foundation walls and strips with a thickness of at least $10 \mathrm{~cm}$. These requirements pertain to extreme conditions (IV climate zone and soil with heat conductivity rate $\lambda>1.5 \mathrm{~W} / \mathrm{m} \cdot \mathrm{K}$ ).

\section{References}

1. B. Biernacka, (Badania doświadczalne naturalnego pola temperatury gruntu, Oficyna wydawnicza PB, 2006)

2. I. Ickiewicz, (Posadowienie fundamentów bezposrednich w funkcji przemarzania gruntów, Rozprawy Naukowe No. 202, Oficyna Wydawnicza PB, 2010)

3. A. W. Lykov, (Tepło $i$ massoobmen $v$ kapilarno-poristych telach, Problemy cieploobmena, Moskwa, 1967)

4. J. A Pogorzelski, (Fizyka cieplna budowli PWN, 1976)

5. J. A. Żuranski, T. Godlewski, (O przemarzaniu gruntu w Polsce Prace naukowe ITB, 2017) 